\title{
Curating Knowledge and Curating Fun: An Analysis of the Expanding Roles of Children's Museums
}

\author{
Sarah C. Harris, Flávio S. Azevedo, Anthony J. Petrosino \\ Department of Curriculum and Instruction, The University of Texas at Austin, Austin, TX, USA \\ Email: sharris21@utexas.edu
}

How to cite this paper: Harris, S. C., Azevedo, F. S., \& Petrosino, A. J. (2018). Curating Knowledge and Curating Fun: An Analysis of the Expanding Roles of Children's Museums. Creative Education, 9, 1881-1896. https://doi.org/10.4236/ce.2018.912138

Received: July 30, 2018

Accepted: September 27, 2018

Published: September 30, 2018

Copyright ( $\odot 2018$ by authors and Scientific Research Publishing Inc. This work is licensed under the Creative Commons Attribution International License (CC BY 4.0).

http://creativecommons.org/licenses/by/4.0/

\section{(c) (7) Open Access}

\begin{abstract}
Museums constantly undergo shifts and changes in the roles and functions they serve in society. We report on the expanding roles of a children's STEAM museum through a case study of two adult-only, fundraising events that the museum implemented. Drawing on both qualitative and quantitative measures, our analysis pursues two complementary threads. First, we seek to characterize those events in detail so that we might understand the events' culture and functioning. Second, we look into the population who frequents the events, focusing specifically on various indicators of socio-economic status. By bringing these analytical threads together, we corroborate the finding that museums are expanding into curating fun experiences that are highly tailored to certain segments of the adult public. Importantly, attending to the empirical details of such processes, we further find that the observed changes 1) directly impact the job demands and require skills of children's museum staff, 2) reify the museum as an important economic agent in the community, and 3) potentially reproduce patterns of inequitable access to STEAM cultural capital, among others.
\end{abstract}

\section{Keywords}

Children's Museum, Adult-Only Events, Social Roles of Museums, Mixed Methods

\section{Introduction}

As with all cultural institutions, museums and science centers are constantly undergoing changes and transformations, which usually stem from various factors and forces. For example, the decline in monies and funding opportunities has pushed these institutions to seek new means to sustain and run their opera- 
tions (Museums \& Commission, 1988). Beginning with the introduction of the now widespread practice of charging admission fees (Macdonald, 2002), these efforts have expanded to include an array of alternative museum programs and events, including docent-led tours (Gray \& Chadwick, 2001), film series, lectures, and gallery demonstrations (Sachatello-Sawyer, 2002).

Adding further financial pressure, museums and science centers have had to respond to the growth of powerful private or for-profit organizations that also cater to the public's discretionary time (Stephen, 2001). For example, theme parks are key competitors for museums, particularly when they move into the educational sector, like Walt Disney's EPCOT Center. In reaction to such market encroachment, museums have added restaurants, meeting rooms, banquet halls, bookstores, and gift shops (Stephen, 2001) to their facilities, in part emulating the business model of those competitors.

Broader cultural trends have also come to bear on the transformative processes of museums. As Weil (2012) points out, for instance, rather than "selling" the collections' societal importance, museums are now identifying visitors' interests and then marketing exhibits/events that cater to these audiences. This seeming reversal in the design logic of curation is partly a response to potential visitors of the Generation Y (Wilkening, Chung, \& Museums, 2009)-a group generally identified by coming of age during the developing prominence of the Internet and cell phones and an emerging prevalence of "curating their lives" (Wilkening, Chung, \& Museums, 2009: p. 93).

In light of such changes and dynamics, some suggest that museums have been steadily shifting their focus from transforming audiences "into a people, a citizenry" (Bennett, 1995: p. 63) to providing fun-content (Daley, 1989) and entertainment that cater to adult audiences (van Aalst \& Boogaarts, 2002). Stephen (2001) echoes this sentiment by stating: “The current culture has swept the modern museum into an unpremeditated role: it is, today, a setting for the recreational experience" (p. 300). (For a broader treatment, see Thomas, 2017.)

Children's museums have recently followed suit and began offering myriad adult-only programming and events. These events usually take place after hours and transform a venue traditionally reserved for children and families into an adult-only space, only to return to its family-oriented mission the next day. Simple internet searches return dozens of children's museums who host adult-only events multiple times annually. For example, Kelley (2016) reports on a children's museum that offers "Corporate Recess" where museum staff lead play-time for team building. Another children's museum implements events themed around alcohol and blends beer tasting with play time in the gallery space.

In spite of these observations, to the best of our knowledge, researchers have yet to produce empirical studies that delve into how exactly museums are shifting or expanding into new roles. Arguably, it is of limited use to know that "people are having fun at the museum" or that "museums are increasingly a part of the entertainment industry." Rather, we must ask such questions as: What 
form does such "fun" take across various kinds of adult-only museum events? How do museum staff plan and design particular instances of entertainment? How is "fun" enacted by event attendees, as they interact on the museum floor? How might people relate to museums as a result of participating in these events? And many others.

In this paper, therefore, we address the aforementioned gap in the literature by reporting on an empirical case study of two adult-only, fundraising events implemented at a local children's STEAM museum. By pursuing a case study, our goal is to advance a rich account of a specific instance of a museum's expanding role as producer of entertainment and to reflect on the impacts these changes might have for museum staff, visitors, and various other participants in the events. Rather than aiming for generalizable results or lessons, then, we seek to provide detailed and varied data and analysis so as to generate further questions and inquiry on the subject.

Our analysis will pursue two threads that complement one another. First, we seek to characterize those museum events in some detail and to map out the specific form of "fun" designed and enacted in the events. We ask: What is the "culture" (broadly construed) of these events? What kinds of activities do they provide attendees? Who provides and staffs these activities? What do attendees seek for in such events? What do they typically do while there? What forms of participation does the culture of adult-only events afford its participants?

Second, we look into the population who frequents the events, focusing specifically on various dimensions and markers of socio-economic status. Put simply, who are the participants at the events? What population do the events generally cater to, if any? Who are they professionally? What are some of their cultural and social habits, such as reading, exercising, and learning patterns?

By triangulating findings from both analytical threads, we will be able to consider the events at various simultaneous levels, including some of their planning, dynamics of floor enactment, participants' roles, goals and general background, and finally some institutional and systemic entailments.

\section{Theoretical Framework}

Our theoretical framework incorporates elements from socio-cultural theories of learning (Lave \& Wenger, 1991), sociological theory (Bourdieu, 1984), and museum studies (Falk \& Dierking, 2016). The blending of these various theoretical perspectives is meant to provide a window into 1) the enacted practices of the museum adult-only events, 2) the population to which they cater, and 3) the broader institutional and societal dynamics that result from the events.

Borrowing from socio-cultural theories of learning, we take it that meaning and "culture" are produced and reproduced in the interactions among participants in a practice, as they go about their shared and personal goals (Lave \& Wenger, 1991). In addition, these interactions unfold within particular historical and material contexts that afford certain forms of participation while constrain- 
ing others. In the case of the children's museum events we investigated, for example, these observations draw attention to the various activities that event attendees participate in, the roles they take on during that process (e.g., creators or investigators), the tone and mood of their interactions, and so on.

Socio-cultural theories of learning also foreground issues relative to the division of labor in the creation and running of the events, as well as the larger system of activities within which the events are inserted (Engeström \& Middleton, 1996). As one might imagine, implementing such adult-only, fundraising events is a complex undertaking and it involves a diverse set of actors. To understand the character of any museum-implemented event (or program), we must attend to the larger systemic links from which the event draws or which it builds.

In complementary fashion, from sociological theory and museum studies, we borrow a focus on social categories known to structure broad aspects of society and its functioning, particularly access to cultural capital (Bourdieu, 1984). For example, museum attendance is a practice historically linked to more affluent segments of society (Penuel, 2017). Moreover, museums (and other cultural institutions) are themselves implicated in producing and reproducing differentiated access to learning resources (Bourdieu, 1984; Gray \& Chadwick, 2001). Changes in museums' roles and functioning might work to disrupt or reproduce such patterns, so we must follow how these mechanisms are manifested in our case.

\section{Methods}

Data collection took place between June 2017 and October 2017 at a children's STEAM museum located in a US southwestern city. The Museum (as we shall call it) was selected for this study because of its regularity in hosting adult-only events about every other month, as well as its commitment to the quality of these events (which we dubbed ANM).

We investigated two focal events, out of the six ANM adult-only events the museum implemented annually. Both events were held between $7 \mathrm{pm}$ and 10 pm. Each ANM event has a storyline or theme that permeates all aspects of the evening, thus creating a topical coherence across event activities. Although each evening explores a different theme, all events include a DJ, several cash bars, special activities, local food trucks, as well as access to the permanent exhibition space. Typically, there are performances by local artists and musicians, and activities and services feature local businesses like tech and gaming industry representatives, scientists, and animation studios.

The first event was held in August 2017 and was themed around Making and Makers-a deliberate link to the "Maker Movement" (Halverson \& Sheridan, 2014) currently popular in STEM education. Deploying some typical tools of Making, participants created such take-home objects as friendship bracelets, sewing projects, and custom laser-etched coasters. The Museum Facebook page advertised: "Who's ready to drink, tinker and make ...? We are! We'll take apart 
electronics, silkscreen patches, learn how to cast bronze swords and MORE. Snag your tickets today-this * will* sell out!”

The second event had a broad Spy theme and was held in October 2017. For this event, each activity was assigned a point value that the attendee earned for completing it. The program had a space for attendees to tally "points" earned from each activity. There were three Spy Levels: Spy Kid ( $<24$ points), Rookie Spy (25 - 49 points), and Agent Provocateur ( $>50$ points). As attendees left, they could pick up a "badge" for the level they achieved.

Within these spaces and given our research questions, we designed the study around various mixed methods of data collection and analysis, each tapping into specific aspects of the phenomena we wished to capture. Let us consider each.

\subsection{Event Observations}

We carried out ethnographically informed observations (Emerson, Fretz, \& Shaw, 2011) of the two focal ANM events and recorded these observations in field notebooks. At both Maker and Spy events, the first author (FA) was a participant observer. At the Maker event, the FA was positioned indoors adjacent to an event activity and a permanent water play exhibit, such that the FA was the first activity people encountered that evening. This position allowed her to converse with many attendees as they first entered the Museum. At the Spy event, the FA observed the event from next to the outdoor playscape-a position that afforded continuous interaction and conversations with numerous attendees, as they waited their turn on the playscape activity.

Overall, observations focused on the routines enacted at the level of individuals, couples or groups of friends, and event activities (Rogoff, 1995). As we have posed: What are people doing at the events? What do they talk about? What is the mood on the floor? What activities are provided and how do attendees interact with them?

\subsection{Staff Interviews}

We conducted semi-structured interviews with five staff members that were key organizers of the events. The goal of the interviews was to explore the professionals' educational background, career experience, as well as their vision and goals for the events. In addition, interviews sought to articulate aspects of the events' design to inform ethnographic-like event observations. Allison (all names are pseudonyms) is the Associate Director of Programs with over fifteen years of experience in children's museum educational programming. Trevor is the Programs Manager and reports directly to Allison. Before joining the museum in early 2017, Trevor coordinated afternoon educational programming for elementary schools in an urban school district. Karen, the Program Coordinator, is overseen by Trevor; she started at the Museum as a volunteer and was hired full-time nine years ago. Lastly, Cameron and Roger are Content Specialists. Both men work primarily with the museum's day-to-day children's 
programming, but they are called upon as resources for the adult-only events.

Interviews took place either in the staff's own office space, outside of the museum building, or at a restaurant in the immediate vicinity of the museum. Each interview lasted about thirty minutes, except for Roger's, which lasted one hour. All sessions were audio recorded and transcribed.

\subsection{Design and Planning Meetings}

To conceive and design the events, the organizers held various meetings with different constituencies. The FA attended two such meetings-one brainstorming session, which lasted 90 minutes, and one planning session, which lasted 45 minutes. All meetings were audio recorded and transcribed, and field notes were taken.

The brainstorming meeting was open to any interested staff member, and it was framed as a space to "simmer" possible activities, where "no idea is a bad idea." Allison led the meeting with twenty staff members in attendance. The planning meeting followed up on the progress of activity preparations, including final confirmation of vendors and the evening's logistical considerations. Both meetings took place within the museum office spaces.

Additionally, the FA visited the museum during normal business hours eight times over the course of the study. These observations focused on the daily operations of the museums as families visited during normal business hours. The FA also observed how the staff prepared for the events while balancing other job duties. The visits lasted between thirty minutes and three hours. Again, all observations were logged in field notes.

\subsection{Attendee's Survey}

During the two events, attendees $(\mathrm{N}=209)$ voluntarily chose to participate in a survey (103 at the Maker event and 106 at the Spy event). The survey had 15 items meant to document attendees' personal data and background (residence zip code, museum membership, and visiting history), habits and lifestyle (reading and exercising preferences, traveling, general museum attendance, and hobbies), and motivations for attending the event.

\subsection{Artifacts}

We collected a variety of artifacts related to the events and the Museum. First, the museum website and social media pages contain useful information on each ANM event's activities, advertisement videos, and pictures of past events. Second, colorful, printed event programs were distributed to attendees upon entering the museum at each event. Each program contains a map of the museum and detailed information about each activity and bar locations. The FA collected printed programs at the two events she attended, and Trevor (Programs Manager) provided the programs for the previous five events. These artifacts informed inferences on the nature of the events and their activities. 


\section{Results}

We begin our analysis with a descriptive account of the events and their "culture." We draw most centrally from field observations of the events and their material artifacts (program, web presence, etc.), but also from staff interviews and planning/brainstorming meeting notes. In doing so, our goal is to create a composite and detailed picture of the phenomena we observed.

We then move into the analysis of the attendee population and its defining characteristics. Here, the primary data are attendee surveys; event observations, staff interviews, and observations of planning/brainstorming meetings are brought in to contextualize and help interpret survey findings.

\subsection{Characterizing the Events}

The Museum was established in the early 1980s, and it is currently housed in a state-of-the-art facility in a rapidly developing neighborhood. The building is two stories with a fenced outdoor exhibit space, for a total of 40,000 square footage. The museum has an annual visitation of about 500,000 across all special events and daily attendance.

At a typical ANM event, the sound of upbeat music from the DJ booth is audible and loud on the sidewalks along the museum. The music was a mix of nostalgic 80 s, modern rock, pop, and techno music. It was not out of place to see a group of friends singing and dancing along during the evening.

Indeed, reflecting this adult-only, fun-centered atmosphere, the museum's website advertised: "Grown-ups get their own night at The Museum! During [the ANM event], we close the museum to kids and let adults, ages 21 and up, eat, drink and mingle while experiencing innovative science and art." The events featured three bar locations spread across the building and staffed by a local distillery. Bars offered a short list of local canned beers and wines, as well as a themed "signature cocktail" ("Maker Mule" and "Spy on the Beach"). At the Maker event, the budget of 600 pounds of ice was used halfway through the night because of the popularity of the "Maker Mule." The featured food vendor at both events was a Korean Mexican fusion food truck outside the main entrance of the museum.

On the floor, women wore sundresses and booties or t-shirts and jeans; men wore shorts or khakis with button-down shirts or the occasional t-shirt. Some attendees dressed in costumes that aligned with the theme of the event. For instance, for the Spy event, some visitors came dressed as their favorite spies, such as Kim Possible (from the children's TV show of the same name) and Lucy Wilde from the Despicable Me film franchise. Some attendees wore generic trench coats, fake mustaches, empty gun holsters, stilettos, and fedora hats.

\section{Activities}

Socializing and drinking unfolded around and through the various activities designed for the events. The Maker event had 30 activities, and the Spy event had 
25. The activities offered to attendees featured local businesses or organizations-referred to by staff as "community partners"-who provided an interactive component, like a photo booth (with theme-aligned props), a station to create art from recyclables, a rabbit petting zoo, etc. Overall, about three to ten people facilitated each activity.

Activities were given clever names, such as "Dip your Wick" (where participants created candles), "Fool for Tools" (in which participants practiced basic hand tool skills), "Nut Launchers" (attendees used a catapult to launch varies items at an outside wall of the museum), and "Sharks with Frickin' Laser Beams" (where attendees staged battles using helium-filled shark-shaped balloons with laser pointers attached). As we can see, activities ran the gamut in what they asked of participants and event planners explicitly worked toward providing variety among them. Some activities highlighted physical effort, others silly play (e.g., making slime), still others the affective dimension (e.g., rabbit petting and dressing). For instance, in "That Girl is ... Poisoned" participants wore eye shift goggles ("drunk goggles") to simulate being poisoned while scaling the two-story, playground climber. At the top, a volunteer distributed the "antidote" (glow bracelets). On the other hand, in "Camp Crafts" participants made friendship bracelets and melted bead art.

While all activities were primarily conceived to support fun-based participation, many had explicit learning goals. For instance, in the Maker event, nearly half of all activities had an explicit learning goal as its central motivator. Many of those were anchored on food and drinking themes, such as "A Piece of (Cup) cake" (where participants learned to decorate cakes), "Getting' Cheesy" (where attendees learned how to make mozzarella cheese), "Beer, Wine, Cheese, \& Pickling-Oh My!" (where a local brewery taught homebrew techniques), "Infuse to Amuse" (where participants learned to infuse vodka), "mastering salsa and tortilla making," and bartending techniques.

Beyond event-specific activities, certain activities cut across ANM events. As an example, there was always a vendor featuring live animals, usually rabbits from a private farm or adoptable puppies and kittens from the local Humane Society. These activities involve "snuggling and cuddling" or dressing up the animals according to the event's theme. For the Spy event, visitors were encouraged to "disguise" a rabbit at the activity "Rabbit Ruse"; at the Maker event, attendees made toys with the Humane Society (“Toys for Furry Friends").

Both focal events also relied on undergraduate and graduate students from local universities. The students facilitated an activity that explained the science behind some component of the theme. For the Spy event, students taught the science of different concealed communications ("Invisible Ink") while at the Maker event, students taught about polymers through making slime ("Satisfying Slime").

Lastly, each event also featured a photo booth with props that aligned with the event's theme. In some cases, like the Spy event, photos were posted to the Fa- 
cebook event site a few days after the event. The Spy event photo booth resulted in almost 200 photos posted on the event's page.

\subsection{Characterizing Event Attendees}

While we did not collect demographic data, triangulating data from staff interviews, survey results, and event observations provide some key insights into the population of ANM attendees. To begin, there was an even split of male and female attendees, and all were at least twenty-one (due to the alcohol age restriction), while most were less than 40 years old.

Most attendees were white, with very few Latinx, African American, and Asian American attendees among the crowd. The survey data showed that $87.4 \%$ of respondents were residents of the county, which represents a diverse range of incomes. Yet, roughly $47 \%$ of respondents reported residing in an affluent, well-educated zip code (Mellnik \& Morello, 2013).

One couple that was highly representative of many attendees is one we came to call the "Acroyoga" couple (Maker event), given their animated description of their "acrobatic yoga" practice and further description of their active lifestyle. The man and woman were white and appeared to be in their mid to late 20s, and both were college educated. The man was muscular and on the shorter side, and he wore a plaid shirt, shorts, and a plaid taxi-driver style cap. He was employed at a local tech company and developed artificial intelligence for video games. The woman was thin and about the same height as the man, with long dark hair worn loose. They both were very happy, smiling, drinking, laughing, and poking fun at one another.

Although each ANM event sold out of tickets, very few of those were sold to museum members-94.7\% of survey respondents reported they were non-members of the Museum. Trevor (Programs Manager) reported that $96.5 \%$ of the all Maker event tickets and $95.5 \%$ of all Spy event tickets were purchased by non-members. Furthermore, $72 \%$ attendees reported being first-time visitors to the site. Only $28 \%$ of attendees were repeat visitors to ANM events, with $7.2 \%$ having visited at least four times. ANM events, therefore, attracted mostly new visitors to the museum; the typical adult Museum member who frequents it with the family is clearly not attending ANM events at the same frequency as non-members. $\mathrm{Mu}$ seum members reasons for not attending the ANM events is outside the scope of this study.

\subsubsection{Reasons for Attending}

The survey results also provided insight into the reasons that brought respondents to the events. Attendees were asked to rank order the importance of five criteria they considered when they purchased tickets for the event: "pleasure and personal satisfaction", "financially support the museum," "relevance to employment," "gaining knowledge and general ability," and "meeting other people" (see Table 1).

Overall, "pleasure and personal satisfaction" was by far the most important 
criterion cited by participants for attending the events (Maker: 56.6\%; Spy: 53.2\%). Interestingly, few people mentioned "meeting other people" as a goal of their visit (Maker: 12.22\%; Spy: 9.18\%), which reinforces our observation that most came accompanied to the event. Also, very few attendees came to ANM events for "gaining knowledge and general ability" (Maker: 9.41\%; Spy: 14.61\%), which reasonably follows from the explicit entertainment-centered nature of the events and attendees' goal of having a fun night out.

\subsubsection{Lifestyle}

Markers of lifestyle and cultural habits reveal much about the population that is ultimately attracted to ANM events. To begin, survey results show attendees pursue hobbies clustering around five topics: Reading (21.5\%), DIY/Crafts (18.7\%), Food (17.2\%), Music (16.7\%), and Arts (13.9\%). Respondents most commonly read the New York Times (18.2\%) and The Washington Post (9.6\%), as well as professional journals (7.2\%) and local city publications (5.7\%). (See Table 2 for a synthesis.)

Table 1. Participants' reasons for attending the two focal ANM events.

\begin{tabular}{ccc}
\hline Criteria & Maker event & Spy event \\
\hline Pleasure and personal satisfaction & $56.6 \%$ & $53.2 \%$ \\
Meeting other people & $12.22 \%$ & $9.18 \%$ \\
Gaining knowledge and general ability & $9.42 \%$ & $14.61 \%$ \\
Financially supporting the museum & $6.35 \%$ & $7.1 \%$ \\
Relevance to employment & $24.4 \%$ & $31.6 \%$ \\
\hline
\end{tabular}

Table 2. A synthetic summaryof attendees' activitiesand habits.

\begin{tabular}{ccc}
\hline & $\begin{array}{c}\text { Attendees' Reported Activities and Habits } \\
\text { (\% of open-ended responses) }\end{array}$ & \\
\hline Activities & Description & Across Events \\
\hline Hobbies & Reading & 21.5 \\
& DIY and Crafts & 18.7 \\
& Food & 17.2 \\
& Music & 16.7 \\
Reading Preferences & Arts & 13.9 \\
& The New York Times & 18.2 \\
& The Washington Post & 9.6 \\
& Professional journals & 7.2 \\
& Local publications & 5.7 \\
& Yoga & 10.0 \\
Sports & Rock Climbing & 8.6 \\
& Tennis & 3.3 \\
\hline
\end{tabular}




\begin{tabular}{ccc}
\hline & Equestrian & 1.0 \\
Paddle boarding & 0.5 \\
Hockey & 0.5 \\
Cultural Activities & Attend museums \& galleries & 76.2 \\
& Attend the opera \& theater & 52.4 \\
& Attend sporting events & 53.0 \\
& Play video games & 48.1 \\
\hline
\end{tabular}

Still, along cultural patterns of consumption and engagement, $76.2 \%$ reported commonly visiting museums/galleries and $52.4 \%$ attended the opera/theater. A large number reported that they visited museums while traveling $(81.5 \%)$, with a cluster of individuals listing MOMA (7.2\%) in particular. Favorite museum types include Art (12.4\%), History (10.0\%), Science (9.6\%) and Natural History (6.7\%).

Furthermore, attendees reported engaging in coursework that led to a qualification (64.8\%); that developed job skills (77.6\%); or taught a craft, sport, or instrument $(46.7 \%)$. Additionally, $74.8 \%$ of visitors reported that they taught themselves a skill without formal coursework. Overall, a very well-educated population, one that actively engages in lifelong learning opportunities of varied kinds (National Research Council, 2009).

Respondents also reported a large range of sports, many of which require costly membership or gym dues and specialized equipment, including yoga (10.0\%), rock climbing $(8.6 \%)$, tennis $(3.3 \%)$, equestrian sports $(1.0 \%)$, paddle boarding $(0.5 \%)$, and hockey (0.5\%) (Table 2). Nearly 53\% attend sporting events and $48.1 \%$ play video games.

Overall, then, we find various indicators of the cultural tastes and preferences of the affluent, middle to upper class, urban, "cosmopolitan" segments of the local society, including reading patterns, museum visiting and traveling, and sports practice. This is in line with survey data that indicate nearly half of attendees resided in affluent ZIP codes, as seen previously.

\section{Discussion}

ANM events typically sell out weeks in advance-a whopping 650 tickets per evening-which attests to the events' success and explains their inclusion in the Museum's regular program schedule for over three years now. In considering such "success cases," our goal has been to inform the work of museum professionals and the discussions regarding the shifting landscape of contemporary (children's) museum practice. By way of discussion, we further elaborate on the above analyses and consider their main lessons.

To begin, ANM events were clearly centered on providing attendees with a social and fun time around drinks, music, and various forms of entertainment 
and action. Whether people came in couples, groups or large parties, they simply enjoyed a good and festive time throughout the night, as they moved across an array of activities designed exclusively for the occasion. Activities ran the gamut in what they offered participants, from acting silly to physical action, play and experimentation, riddle solving, making myriad artifacts, rabbit petting and dressing up, and much more. The highly coveted rabbit petting booth is perhaps emblematic of the highly tailored forms of participation afforded to attendees-an activity exclusive to ANM events and absent from the Museum's regular offerings to its family-oriented audience, where it might seem to belong more appropriately.

In all, therefore, we find further evidence that museums continue expandingtheirroles and functionsin society (Stephen, 2001). Long ago, Jack Lang (former French Minister of Culture) wrote that "museums must offer cinemas, auditoriums, pleasant restaurants, rest areas, bookstores, boutiques, and gardens. Simply put, the museum must be receptive to the spirit and flesh of human beings" (Davis, 1990: p. 7). Then as well as now, the museum has become "a place of traditional and newly-redefined cultural functions" and a space for the search of entertainment and pleasure (Davis, 1990; Thomas, 2017). These newly-redefined cultural functions are enacted on all events/programs, whether a fundraiser or not.

The case of ANM events and the Museum embodies a particular instantiation of that phenomenon-one which reflects historically, socio-economically situated forms of cultural expression and trends, such as those linked to the Maker movement (Halverson \& Sheridan, 2014). No longer is it enough to curate a collection of artifacts, specimens, learning activities, and workshops designed around collections. Instead, children's museums must also curate fun, elaborate events conceived exclusively for the adult public, as part of their scheduled operating grid. Such events require significant planning, research, creativity, collaboration, and time to put together. Their execution is intense and laborious, and they require substantive human, material, and infrastructural resources, as well asongoing coordination work among the various involved parties.

Two immediate implications follow from these observations. First, with regard to the daily operation of the Museum, we find that practices of curating fun do not necessarily align with those of curating STEAM knowledge and learning experiences that such children's museums are typically charged with. Put simply, as currently implemented, designing for fun at ANM events has had little to do with the STEM learning designs that regularly populate exhibits at children's museums. This means that museum staff must learn new skills of design and adapt to shifting job demands, and professional development efforts must equally respond to these emergent demands so as to appropriately support staff.

Further corroborating these inferences, our field observations show that $\mathrm{cu}-$ rating fun at the Museum makes minimal use of the museum exhibit infrastructure. Activities provided by community partners "snaked around" permanent exhibits and experiment stations, and they hauled into the museum floor their 
own material infrastructure for implementation. So the complexity of conceiving designs for fun is further compounded by the need to imagine and design activities centered on extraneous infrastructure. We are currently investigating the details of the Museum's ANM event planning and design, with the goal of distilling what might be principles for curating fun experiences.

The second implication resides at the systemic level. As it stands, the $\mathrm{Mu}$ seum's model of curating fun appears to deepen the institution's role as an economic agent in the community and local culture of the city. As previously considered, community partners are key participants in ANM events, and they provided essentially all services for the night-from food (drawn from popular food trucks), drinks (award-winning local distillery and breweries) and music, to the substantive activities that animate the night. In turn, community partners employ a large spectrum of the labor force-an estimated average of 90 workers per event-including artists, musicians and DJs, bartenders, hourly workers, graduate students and researchers from local Universities, and many others. The institution thus creates economic links to a wide variety of local businesses, cultural actors, and the broader workforce. Reflexively, the Museum is reified as an element in the production chain at the intersection of cultural, leisure, and entertainment sectors (Rodríguez-Ferrándiz, 2013; Savage et al., 2013). Investigating the economic linkages and entailments of ANM (and similar) events is itself an important long-term project.

Still at the systemic level, as we have considered, ANM events draw mostly from the upper socio-economic segments of the local society and implicitly selects for certain ethnic groups. While this might be expected of fundraising events, and indeed from general patterns of museum attendance of different ethnic groups (Penuel, 2017), ANM events can be seen to inadvertently reproduce patterns of inequitable access to STEM cultural resources. Crucial here is the specific mechanism through which this operates.

To explicate, it is a fact that attending the events literally buys a person discretionary time to engage the Museum collection in a privileged, highly tailored (e.g., children-free, alcohol-fueled), interest-driven, self-paced format. This is true whether or not the visitor intentionally makes any use of the Museum infrastructure for learning during the event-which is a privilege in its own right. The most significant fact, however, is that attending ANM events affords participants an opportunity to experience the museum in a new and unique way-that is, as a space for fun and distinctive forms of entertainment and pleasure (Bourdieu, 1984), all of which expand how one might live the museum experience. By interacting with museums as both institutions of learning and fun and entertainment, one is afforded the chance to create diverse, expanded, and multifaceted relationships to museum settings. In doing so, ANM events offer attendees a differentiated opportunity to inhabit, appropriate, and claim ownership of the museum ideology and physical space, in ways not ordinarily available to all social groups. 
We recognize that the Museum implements other events explicitly and effectively catering to diverse and underrepresented groups, and we commend these and related efforts. From the analytical perspective employed here, however, any such event or program (fun-centered or not) will necessarily afford some kinds of museum experiences while constraining others, which in turn will afford the visitor developing some kinds of relationships (but not others) to that institution. Willingly or not, some such events will likely reproduce inequitable patterns of access to museum space and STEM cultural capital, while others might afford opportunities for contesting such processes (Philip \& Azevedo, 2017). We know very little about these events and further investigating them can provide key insights into their functioning and implications.

\section{Concluding Thoughts}

As children's museums continue to respond to the inevitable shifts in the social, cultural, and economic contexts in which they operate, it seems natural that they come to diversify their events, services, and public offerings and, thus, to extend beyond their traditional charter of curating knowledge and learning. Our work here was meant to shed light on some of the basics of a museum's implementation of curating fun experiences for adult audiences and the major implications these new roles might have across a range of actors, in and outside that institution.

As we stated from the outset, we did not aim for generalizable results but instead sought to provide data-rich narratives and analyses that can open novel entry points for empirical research on the expanding roles of children's museums. It is our hope that the continued pursuit of these issues will raise new questions and insights that ultimately work to fulfill the democratic and educational ideals of museums.

\section{Acknowledgements}

We are deeply indebted to the Museum for granting us generous access to its installations, events, and daily operations, as well as its staff for their time and unwavering support throughout the research period.

\section{Conflicts of Interest}

The authors declare no conflicts of interest regarding the publication of this paper.

\section{References}

Bennett, T. (1995). The Birth of the Museum. London, UK: Routledge.

Bourdieu, P. (1984). Distinction: A Social Critique of the Judgment of Taste. Cambridge, MA: Harvard University Press.

Daley, J. (1989). The Mr. Crapper Approach to Art. The Independent, 25.

Davis, D. (1990). The Museum Transformed: Design and Culture in the Post-Pompidou Age. New York City: Abbeville Press. 
Emerson, R. M., Fretz, R. I., \& Shaw, L. L. (2011). Writing Ethnographic Fieldnotes. Chicago, IL: University of Chicago Press.

https://doi.org/10.7208/chicago/9780226206868.001.0001

Engeström, Y., \& Middleton, D. (1996). Cognition and Communication at Work. Cambridge, MA: Cambridge University Press. https://doi.org/10.1017/CBO9781139174077

Falk, J., \& Dierking, L. (2016). The Museum Experience Revisited. New York, NY: Routledge. https://doi.org/10.4324/9781315417899

Gray, D., \& Chadwick, A. (2001). Museums: Using Keyworkers to Deliver Lifelong Learning. International Review of Education, 47, 427-441. https://doi.org/10.1023/A:1012228714243

Halverson, E. R., \& Sheridan, K. M. (2014). The Maker Movement in Education. Harvard Educational Review, 84, 495-504. https://doi.org/10.17763/haer.84.4.34j1g68140382063

Kelley, D. (2016). Play on: The Importance of Adult-Only Play Events at Children's Museums. Master of Arts, University of Washington.

Lave, J., \& Wenger, E. (1991). Situated Learning: Legitimate Peripheral Participation. Cambridge, UK: Cambridge University Press. https://doi.org/10.1017/CBO9780511815355

Macdonald, S. (2002). Behind the Scenes at the Science Museum. New York, NY: Berg Publishers.

Mellnik, T., \& Morello, C. (2013). Washington: A World Apart. http://www.washingtonpost.com/sf/local/2013/11/09/washington-a-world-apart/

Museums \& Commission (1988). The National Museums: The National Museums and Galleries of the United Kingdom. London: HMSO.

National Research Council (2009). Learning Science in Informal Environments: People, Places, and Pursuits. In Committee on Learning Science in Informal Environments, P. Bell, B. Lewenstein, A. W. Shouse, and M. A. Feder (Eds.), Board of Science Education, Center for Education, Division of Behavioral and Social Sciences and Education. Washington, DC: The National Academy Press.

Penuel, W. (2017). Research-Practice Partnerships as a Strategy for Promoting Equitable Science Teaching and Learning through Leveraging Everyday Science. Science Education, 101, 520-525. https://doi.org/10.1002/sce.21285

Philip, T. M., \& Azevedo, F. S. (2017). Everyday Science Learning and Equity: Mapping the Contested Terrain. Science Education, 101, 526-532.

https://doi.org/10.1002/sce.21286

Rodríguez-Ferrándiz, R. (2013). Culture Industries in a Postindustrial Age: Entertainment, Leisure, Creativity, Design. Critical Studies in Media Communication, 31, 327-341. https://doi.org/10.1080/15295036.2013.840388

Rogoff, B. (1995). Observing Sociocultural Activity on Three Planes: Participatory Appropriation, Guided Participation, and Apprenticeship. In J. V. Wertsch, P. del Rio, \& A. Alvarez (Eds.), Sociocultural Studies of Mind (pp. 139-163). Cambridge: Cambridge University Press. https://doi.org/10.1017/CBO9781139174299.008

Sachatello-Sawyer, B. (2002). Adult Museum Programs: Designing Meaningful Experiences. Lanham, MD: Altamira Press.

Savage, M., Devine, F., Cunningham, N., Taylor, M., Li, Y., Hjellbrekke, J., Miles, A. et al. (2013). A New Model of Social Class? Findings from the BBC's Great British Class Survey Experiment. Sociology, 47, 219-250. https://doi.org/10.1177/0038038513481128

Stephen, A. (2001). The Contemporary Museum and Leisure: Recreation as a Museum Function. Museum Management and Curatorship, 19, 297-308. 
https://doi.org/10.1080/09647770100601903

Thomas, L. (2017). Too Much Fun: Contemporary Aesthetic Theory and Design. Design and Culture, 9, 301-315. https://doi.org/10.1080/17547075.2017.1370669

Van Aalst, I., \& Boogaarts, I. (2002). From Museum to Mass Entertainment: The Evolution of the Role of Museums in Cities. European Urban and Regional Studies, 9, 195-209.

Weil, S. (2012). Making Museums Matter. Washington DC: Smithsonian Institution.

Wilkening, S., Chung, J., \& Museums, A. A. O. (2009). Life Stages of the Museum Visitor: Building Engagement over a Lifetime. Arlington, VA: AAM Press. 